\title{
NMR assignments of the macro domain from severe acute respiratory syndrome coronavirus 2 (SARS-CoV-2)
}

\author{
Meng-Hsuan Lin ${ }^{1} \cdot$ Yi-Ping Huang ${ }^{2} \cdot$ Chi-Fon Chang ${ }^{2} \cdot$ Chun-Hua Hsu $^{1,3,4}$
}

Received: 2 September 2020 / Accepted: 11 December 2020 / Published online: 24 January 2021

(c) The Author(s), under exclusive licence to Springer Nature B.V. part of Springer Nature 2021

\begin{abstract}
SARS-CoV-2 is a novel pathogen causing pneumonia named COVID-19 and leading to a severe pandemic since the end of 2019. The genome of SARS-CoV-2 contains a macro domain that may play an important role in regulating ADP-ribosylation in host cells and initiating viral replication. Here, we report the ${ }^{1} \mathrm{H},{ }^{13} \mathrm{C}$, and ${ }^{15} \mathrm{~N}$ resonance assignments of the SARS-CoV-2 macro domain. This work provides the ground for further structural deciphering and biophysical investigation in protein function and antiviral agent design.
\end{abstract}

Keywords COVID-19 $\cdot$ SARS-CoV-2 $\cdot$ Macro domain $\cdot$ Viral protein

\section{Biological context}

A novel virus, SARS-CoV-2 (Severe Acute Respiratory Syndrome Coronavirus 2, also called 2019-nCoV), was identified as the pathogen that caused the pandemic of emerged pneumonia-like disease, COVID-19, since the December of 2019. Based on the genome analysis of SARS-CoV-2, a macro domain was found in nonstructural protein 3 (NSP3). Viral macro domains had been reported possessing

\section{Supplementary Information The online version of this article} (https://doi.org/10.1007/s12104-020-09996-x) contains

supplementary material, which is available to authorized users.

Meng-Hsuan Lin and Yi-Ping Huang have contributed equally to this work.

Chi-Fon Chang

chifon@gate.sinica.edu.tw

$\triangle$ Chun-Hua Hsu

andyhsu@ntu.edu.tw

1 Genome and Systems Biology Degree Program, National

Taiwan University and Academia Sinica, Taipei 10617,

Taiwan

2 Genomics Research Center, Academia Sinica, Taipei 11529, Taiwan

3 Department of Agricultural Chemistry, National Taiwan University, Taipei 10617, Taiwan

4 Institute of Biochemical Sciences, National Taiwan University, Taipei 10617, Taiwan multifunction, for instance, interactions with ADP-ribose (ADPR) (Cho et al. 2016; Egloff et al. 2006; Makrynitsa et al. 2019), poly-ADPR (Egloff et al. 2006) or adenine-rich RNAs (Tsika et al. 2019); ADPR-1" phosphate dephosphorylation (Egloff et al. 2006; Saikatendu et al. 2005); and enzyme activity as an ADPR-protein hydrolase( $\mathrm{Li}$ et al. 2016). Accumulated evidence about viral macro domains indicated a critical relevance to host cellular ADP-ribosylation, one of post-translational modification which correlated to DNA repair, transcription, and innate immune response (Alhammad and Fehr 2020; Fehr et al. 2020). Moreover, according to studies about viral macro domains from the mouse hepatitis virus (Eriksson et al. 2008) and Sindbis virus (Park and Griffin 2009), viral replications would be depressed while ADPR binding abilities being disrupted by introducing mutations into these viral macro domains.

SARS-CoV-2 harbored a macro domain in its NSP3, so that, SARS-CoV-2 macro domain might play important roles in modulating host ADP-ribosylation and in viral replication. Indeed, there remained many mysteries about the function of the viral macro domain. However, this viral protein obviously is a possible target of antiviral agents. Here, we present the resonance assignment of the SARS-CoV-2 macro domain by a series of NMR experiments. This work would pave the way to the elucidation of the SARS-CoV-2 macro domain solution structure, which may be the base of the COVID-19 antiviral drug design targeting to SARS-CoV-2 macro domain. 


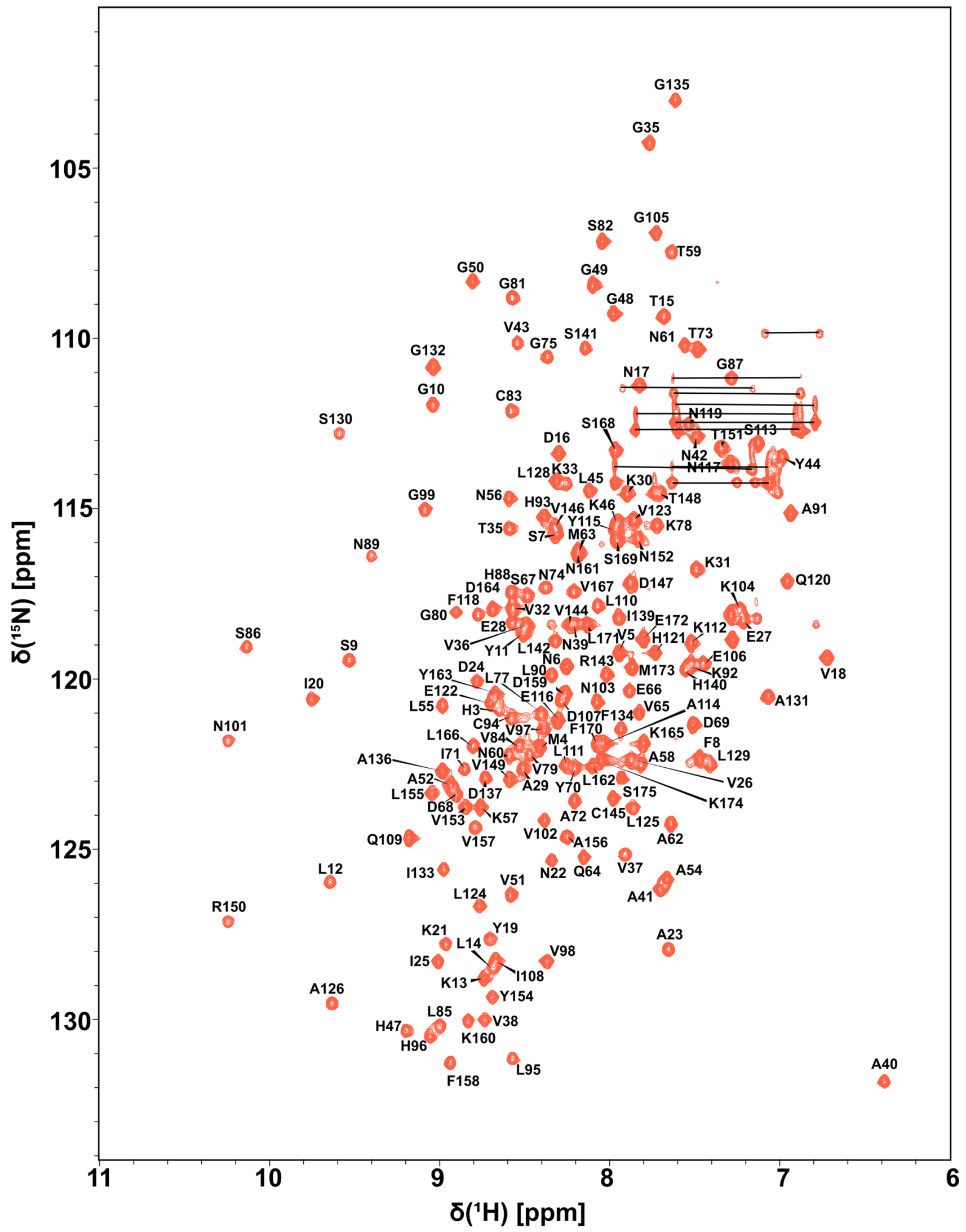


४Fig. $1{ }^{1} \mathrm{H}_{-}{ }^{15} \mathrm{~N}$ HSQC spectrum of SARS-CoV-2 macro domain recorded at $600 \mathrm{MHz}$ with a cryogenic-probe with phosphate buffer pH 6.0 at $298 \mathrm{~K}$. Backbone amide ${ }^{1} \mathrm{H}$ and ${ }^{15} \mathrm{~N}$ cross-peaks are presented. The horizontal lines connect pairs of the side-chain protons from amino acids Asn and Gln

\section{Protein expression and purification}

The protein production of the SARS-CoV-2 macro domain is similar to our previous work on MERS-CoV macro domain. Briefly speaking, the DNA fragment of the SARS-CoV-2 macro domain was synthesized and cloned into the pET-28a $(+)$ vector (Novagen) between the NdeI and XhoI sites. This resulting plasmid was then transformed into $E$. coli BL21 (DE3), grown at $37^{\circ} \mathrm{C}$ up to $\mathrm{OD}_{600} 0.6$, using medium $\mathrm{M} 9$ with $1 \mathrm{~g} / \mathrm{l}$ of $\mathrm{NH}_{4} \mathrm{Cl}$ and D-glucose. After inducing with $1 \mathrm{mM}$ isopropyl- $\beta$-D-thiogalactoside (IPTG) and incubation overnight at $16^{\circ} \mathrm{C}, E$. coli cells would be gathered by centrifugation at $6000 \mathrm{rpm} 10 \mathrm{~min}$ and resuspended by lysis buffer (25 mM phosphate buffer, pH 7.0, $100 \mathrm{mM} \mathrm{NaCl}$ ) followed by $20 \mathrm{~min}$ sonication. The supernatant was then separated from the pellet by centrifugation at $13,000 \mathrm{rpm}$ and $4{ }^{\circ} \mathrm{C}$ for $20 \mathrm{~min}$. The recombinant SARS-CoV-2 macro domain with $\mathrm{N}$-terminal His-tag was purified by $\mathrm{Ni}^{2+}-\mathrm{NTA}$ column with $300 \mathrm{mM}$ imidazole elution. The purified protein was dialyzed against lysis buffer with $0.5 \mathrm{mM}$ dithiothreitol (DTT). The N-terminal His-tag was removed by thrombin cleavage incubating at $10^{\circ} \mathrm{C}$ overnight. The protein product with four additional residues (GSHM) at the N-terminus was further purified by gel filtration chromatography with column Superdex 75 increase 16/60 (GE healthcare).

\section{NMR experiments}

NMR experiments were collected on Bruker Avance 600 and $800 \mathrm{MHz}$ spectrometers at $310 \mathrm{~K}$ with $5 \mathrm{~mm}$ triple resonance cryoprobe and $\mathrm{Z}$-gradient. The collected data were acquired and processed using the software Topspin2.1 (Bruker, Germany) and further analyzed using SPARKY(Lee et al. 2015). ${ }^{1} \mathrm{H}$ chemical shifts were externally referenced to $0 \mathrm{ppm}$ using standard chemical 2,2-dimethyl-2-silapentane-5-sulfonate. ${ }^{15} \mathrm{~N}$ and ${ }^{13} \mathrm{C}$ chemical shifts were indirectly referenced to IUPAC recommendations (Markley et al. 1998). Protein backbone assignments were based on triple resonance experiments: HNCACB, CBCA(CO)NH, HNCA, HNCO, and HN(CA) $\mathrm{CO}$. Side-chain assignments were based on $13 \mathrm{C}-\mathrm{HCCH}-$ TOCSY and 13C-(H)CCH-TOCSY.

\section{NMR assignment and deposition}

The recombinant macro domain of SARS-CoV-2 with a molecular weight of $18.8 \mathrm{kDa}$ contains 171 amino acids and 4 additional $\mathrm{N}$-terminal residues (to which the number $-3,-2,-1,0$ are assigned). The backbone assignments of the SARS-CoV-2 macro domain were almost completed under the experimental conditions ( $\mathrm{pH} 6.0$ at 298K). Completeness of the backbone and side-chain resonances assignments, estimated by CYANA3.98 (Guntert 2004), is $91.6 \%$. Except for five prolines (P30, P72, P96, P123, P134), 98.8\% of backbone amides (168/170) were assigned while the unassigned residues were G-3and S-2. The $2 \mathrm{D}{ }^{1} \mathrm{H}_{-}{ }^{15} \mathrm{~N}$ HSQC spectrum and amide resonance assignments are shown in Fig. 1. The side-chain assignments were also completed. $98.5 \%$ of ${ }^{1} \mathrm{H} \beta, 100 \%$ of ${ }^{13} \mathrm{C} \beta, 83.3 \%$ of ${ }^{1} \mathrm{H} \gamma$, and $66.6 \%$ of ${ }^{13} \mathrm{C} \gamma$ were assigned. The methyl region of the $2 \mathrm{D}{ }^{1} \mathrm{H}-{ }^{13} \mathrm{C}$ HSQC spectrum with the side-chains assignments of residues are shown in Fig. 2.

The secondary structural population of SARS-CoV-2 macro domain was predicted by deviations between $\mathrm{C} \alpha$ and $\mathrm{C} \beta$ chemical shift $\left(\Delta \delta^{13} \mathrm{C} \alpha-\Delta \delta^{13} \mathrm{C} \beta\right)$, and TALOS+(Shen et al. 2009). The results indicated that the SARS-CoV-2 macro domain consisted of seven $\beta$-strands and six $\alpha$-helices (Fig. 3). The chemical shift assignments 


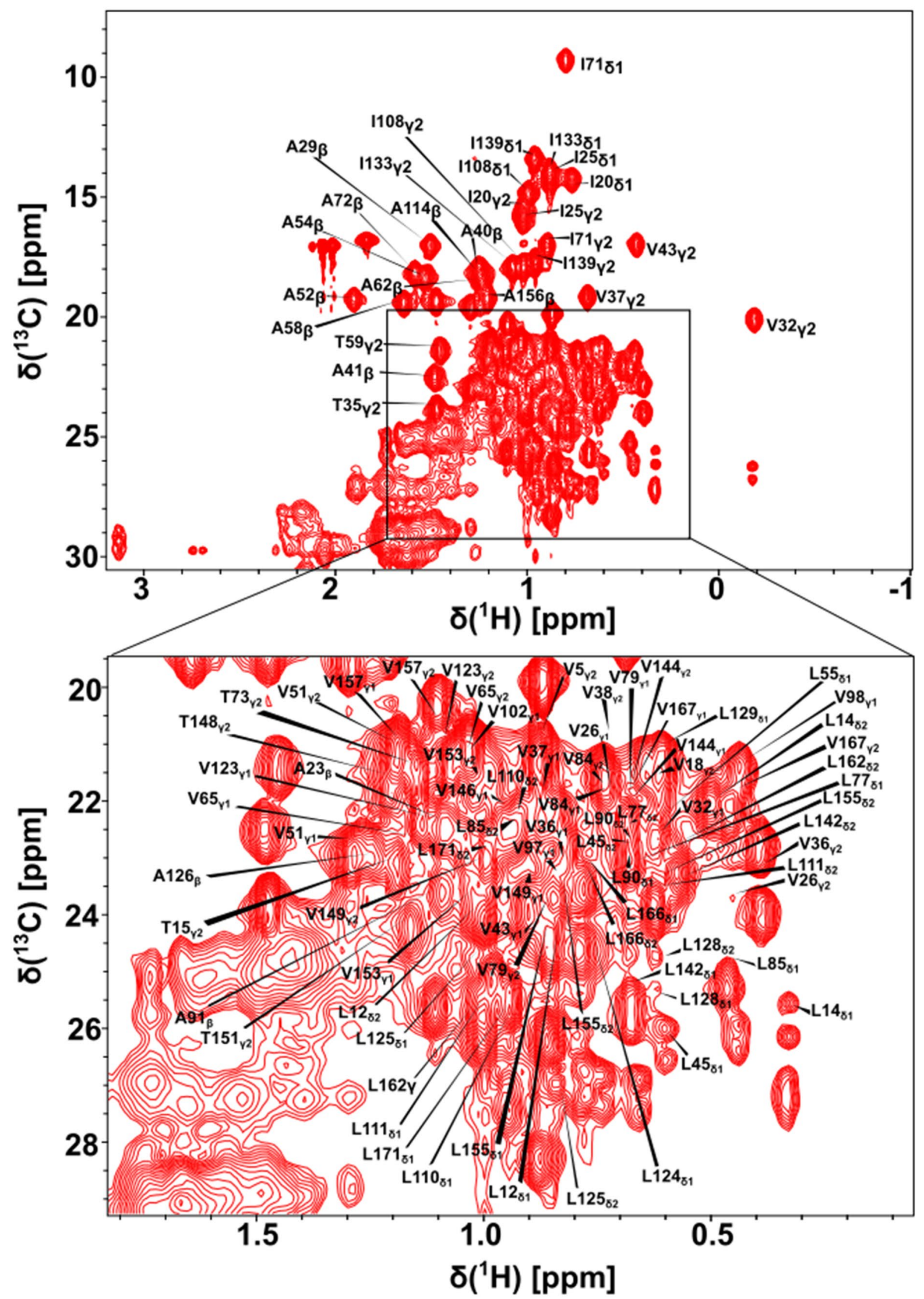


4Fig. $2{ }^{1} \mathrm{H}-{ }^{13} \mathrm{C}$ HSQC methyl correlation spectrum of SARS-CoV-2 macro domain recorded at $600 \mathrm{MHz}$ with a cryogenic-probe with phosphate buffer pH 6.0 at $298 \mathrm{~K}$. The assigned methyl cross peaks are labeled of the SARS-CoV-2 macro domain at $298 \mathrm{~K}$ and $\mathrm{pH} 6.0$ were deposited in the Biological Magnetic Resonance Data Bank (http://www.bmrb.wisc.edu) under accession number 50422.

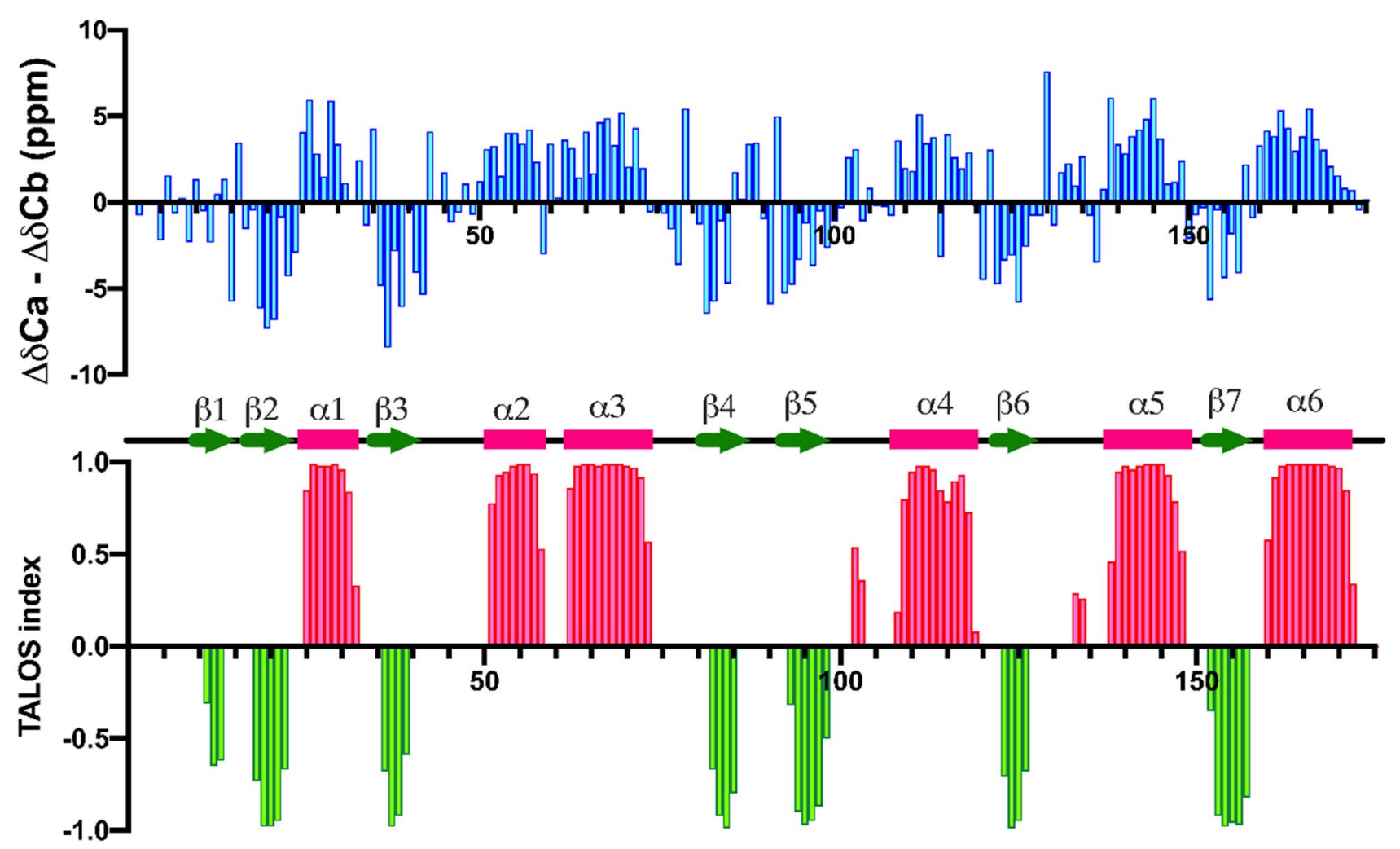

\section{Residue number}

Fig. 3 The secondary structure of SARS-CoV-2 macro domain is predicted by $\mathrm{C} \alpha \mathrm{C} \beta$ chemical shift difference, and TALOS+. Upper panel is the parameter $\Delta \delta C \alpha-\Delta \delta C \beta$ shows the deviation of $\mathrm{C} \alpha$ and $\mathrm{C} \beta$ experimental values from the corresponding random coil values. Positive and negative values suggest $\alpha$-helix and $\beta$-strand structure, respectively. Lower panel is TALOS + index showing the prediction of secondary structure distribution based on backbone $\mathrm{N}, \mathrm{H}, \mathrm{C} \alpha$, $\mathrm{H} \alpha, \mathrm{C}$, and side-chain $\mathrm{C} \beta$ chemical shift values. Negative and positive values suggest $\alpha$-helix (in pink) and $\beta$-strand (in green) structure, respectively. Chemical shift analysis resulting in secondary structure elements of the macro domain is represented 
Acknowledgements The NMR spectra were obtained at the High-field NMR Center, Academia Sinica (AS-CFII-108-112). This work is supported by National Taiwan University (NTU CC- 109L893501 and NTU 109L7734) and the Ministry of Science and Technology, Taiwan (MOST 108-2113-M-002-011, MOST 109-2113-M-002-003, MOST 108-2628-B-002-013 and MOST 109-2628-B-002-037).

\section{References}

Alhammad YMO, Fehr AR (2020) The viral macrodomain counters host antiviral ADP-ribosylation. Viruses 12:384. https://doi. org/10.3390/v12040384

Cho CC, Lin MH, Chuang CY, Hsu CH (2016) Macro domain from middle east respiratory syndrome coronavirus (MERS-CoV) is an efficient ADP-ribose binding module: CRYSTAL STRUCTURE AND BIOCHEMICAL STUDIES. J Biol Chem 291:4894-4902. https://doi.org/10.1074/jbc.M115.700542

Egloff MP et al (2006) Structural and functional basis for ADP-ribose and poly(ADP-ribose) binding by viral macro domains. J Virol 80:8493-8502. https://doi.org/10.1128/JVI.00713-06

Eriksson KK, Cervantes-Barragan L, Ludewig B, Thiel V (2008) Mouse hepatitis virus liver pathology is dependent on ADPribose-1"-phosphatase, a viral function conserved in the alphalike supergroup. J Virol 82:12325-12334. https://doi.org/10.1128/ JVI.02082-08

Fehr AR, Singh SA, Kerr CM, Mukai S, Higashi H, Aikawa M (2020) The impact of PARPs and ADP-ribosylation on inflammation and host-pathogen interactions. Genes Dev 34:341-359. https://doi. org/10.1101/gad.334425.119

Guntert P (2004) Automated NMR structure calculation with CYANA. Methods Mol Biol 278:353-378. https://doi.org/10.1385/1-59259 $-809-9: 353$
Lee W, Tonelli M, Markley JL (2015) NMRFAM-SPARKY: enhanced software for biomolecular. NMR Spectrosc Bioinform 31:13251327. https://doi.org/10.1093/bioinformatics/btu830

Li C, Debing Y, Jankevicius G, Neyts J, Ahel I, Coutard B, Canard B (2016) Viral macro domains reverse protein ADP-ribosylation. J Virol 90:8478-8486. https://doi.org/10.1128/JVI.00705-16

Makrynitsa GI et al (2019) Conformational plasticity of the VEEV macro domain is important for binding of ADP-ribose. J Struct Biol 206:119-127. doi:https://doi.org/10.1016/j.jsb.2019.02.008

Markley JL et al (1998) Recommendations for the presentation of NMR structures of proteins and nucleic acids. IUPAC-IUBMBIUPAB Inter-Union Task Group on the Standardization of Data Bases of Protein and Nucleic Acid Structures Determined by NMR Spectroscopy. J Biomol NMR 12:1-23. https://doi. org/10.1023/a:1008290618449

Park E, Griffin DE (2009) The nsP3 macro domain is important for Sindbis virus replication in neurons and neurovirulence in mice. Virology 388:305-314. https://doi.org/10.1016/j.virol .2009.03.031

Saikatendu KS et al (2005) Structural basis of severe acute respiratory syndrome coronavirus ADP-ribose-1"-phosphate dephosphorylation by a conserved domain of nsP3. Structure 13:1665-1675. https://doi.org/10.1016/j.str.2005.07.022

Shen Y, Delaglio F, Cornilescu G, Bax A (2009) TALOS+: a hybrid method for predicting protein backbone torsion angles from NMR chemical shifts. J Biomol NMR 44:213-223. https://doi. org/10.1007/s10858-009-9333-Z

Tsika AC et al (2019) Deciphering the nucleotide and RNA binding selectivity of the mayaro virus macro domain. $\mathrm{J}$ Mol Biol 431:2283-2297. https://doi.org/10.1016/j.jmb.2019.04.013

Publisher's Note Springer Nature remains neutral with regard to jurisdictional claims in published maps and institutional affiliations. 